\title{
Correction to: The Moderating Effect of Geographic Area on the Relationship Between Age, Gender, and Information and Communication Technology Literacy and Problematic Internet Use, by Yu L, Recker M, Chen S, Zhao N, and Yang Q. Cyberpsychol Behav Soc Netw 2018;21(6):367-373. DOI: 10.1089/cyber.2017.0503
}

\begin{abstract}
J The June 2018 Issue of Cyberpsychology, Behavior, and Social Networking (vol. 21, no. 6, pp. 367-373), the article “The Moderating Effect of Geographic Area on the Relationship Between Age, Gender, and Information and Communication Technology Literacy and Problematic Internet Use," by Dr. Liang Yu et al., there are errors in Figure 2 and in the description of the data presented in Figure 2, which appear in the Results section. The passage referring to the figure was originally printed as:
\end{abstract}

Figure 2 shows that age significantly predicted PIU $(\beta=1.44, \mathrm{t}=4.71, \mathrm{p}<0.001)$ for the group in the urban area, whereas age did not have a significant effect on PIU $(\beta=0.38, t=1.25, \mathrm{p}=0.21)$ for the group in rural areas.

It should read:

Figure 2 shows that age significantly predicted PIU $(\beta=\mathbf{1 . 8 3}, \mathrm{t}=\mathbf{3 . 2 0}, \mathrm{p}<\mathbf{0 . 0 1})$ for the group in the rural area, whereas age did not have a significant effect on PIU $(\beta=\mathbf{0 . 9 1}, \mathrm{t}=\mathbf{1 . 0 0}, \mathrm{p}=\mathbf{0 . 3 2})$ for the group in urban areas.

The online version of the article has been corrected to reflect these changes and the figure has been replaced.

The authors wish to apologize for the error.

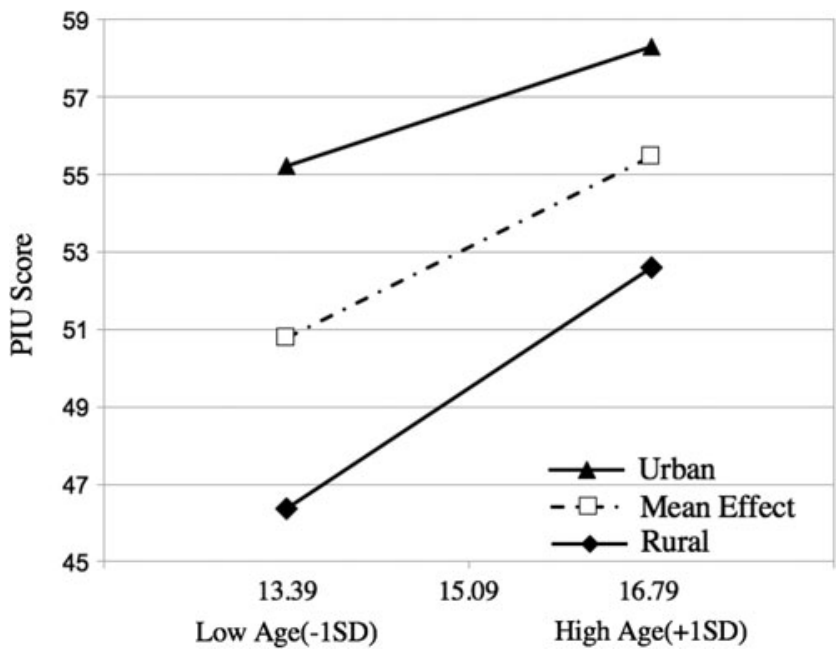

